\title{
Life-Sustaining Treatment in End-Stage Liver Disease Patients: Patients' Decisions and Results
}

\author{
Hyun Jung Jung, R.N., MSN. and Jeong Yun Park, R.N., Ph.D.* \\ Department of Nursing, Asan Medical Center, "Department of Clinical Nursing, University of Ulsan, Seoul, Korea
}

Purpose: In 2018, the Act on Decisions on Life-Sustaining Treatment for Patients in Hospice and Palliative Care or at the End of Life was implemented and the scope of official recognition for terminally ill patients was expanded. The purpose of this study was to investigate the decisions made by patients with end-stage liver disease about their life-sustaining treatment in a clinical setting. Methods: The subjects of this study were patients with endstage liver disease hospitalized at a tertiary hospital in Seoul, Korea who wrote physician orders for life-sustaining treatment (POLST). Data collection was done using patients' electronic medical records, and a retrospective analysis of POLST was conducted. Results: Among 101 patients, $18.8 \%$ were female and $81.2 \%$ were male, and their mean age was $61.8( \pm 10.61)$ years. Sixty-three patients $(62.4 \%)$ wrote their POLST by themselves. Three patients withdrew the POLST, of whom two did so for liver transplantation, and one did so for chemotherapy. Conclusion: This study shows that sufficient consideration of liver transplantation is needed for end-stage liver disease patients before making decisions on life-sustaining treatment. The self-determination of patients must be respected and effective guidelines are urgently needed.

Key Words: Advance directives, Life support care, Terminal care, End stage liver disease, Liver transplantation
Received February 22, 2020

Revised April 28, 2020

Accepted April 29, 2020

\author{
Correspondence to \\ Jeong Yun Park \\ ORCID: https://orcid.org/0000-0002- \\ 0210-8213 \\ E-mail:pjyun@ulsan.ac.kr
}

\section{INTRODUCTION}

As developments in medical science have led to a longer average lifespan, it has become more common for people to live longer despite being affected by various health conditions. Consequently, more people are suffering from psycho-social and functional issues for an extended amount of time, increasing the need for palliative and life-sustaining treatment [1].

In Korea, the Act on Hospice and Palliative Care and Decisions on Life-Sustaining Treatment for Patients at the End of Life (hereinafter referred to as the Act on Decisions on LifeSustaining Treatment) was passed in 2016 and came into force in February 2018 [2]. The subjects of the act include not only patients with carcinoma or similar conditions, but also those with AIDS, chronic obstructive pulmonary diseases, and chronic liver cirrhosis. As of 2019, the act extended coverage to all patients who are at terminal stages of illness or the end of life, regardless of their medical conditions [3].

Patients with chronic liver conditions frequently develop liver cirrhosis due to extended exposure to inflammation within the liver resulting from chronic hepatitis $\mathrm{B}$, hepatitis $\mathrm{C}$, or regular and excessive intake of alcohol or other materials toxic to liver function. In Korea, the prevalence of liver cirrhosis is high, and it is one of the major causes of liver cancer [4,5]. As the 
disease progresses, patients may experience symptoms such as pain from ascites, nausea, dyspnea, and edema, and suffer from physical and mental pain due to peritonitis, variceal hemorrhage, and hepatic encephalopathy [6]. When a patient enters the terminal stage, at which point improvement of the condition cannot be expected, it is necessary to embark on a decision-making process regarding the administration of lifesustaining care, including cardiopulmonary resuscitation, respirators, endotracheal intubation, vasopressors, and hemodialysis. Patients with end-stage liver disease tend to experience sudden, but irreversible deterioration in their conditions. The progression of the disease can be so fast that many patients die lacking time to receive sufficient treatment. Moreover, as there is no clear benchmark to determine the terminal stage of liver disease, sometimes patients decide to discontinue treatment even when it remains possible for their condition to improve [6]. Furthermore, there may be limitations in discussing decisions on life-sustaining care in patients with chronic hepatic encephalopathy due to their impaired judgment or consciousness and/or communication problems. Therefore, the medical team needs to provide ample time for deciding upon the direction of life-sustaining care while a patient retains the ability to make an informed decision, in order for patients with chronic liver disease to exercise their right to self-determination to the full extent [7].

Unlike other patients in terminal stages or hospice care, $\mathrm{pa}^{-}$ tients with chronic liver disease may expect meaningful recovery through liver transplantation [8]. Therefore, many patients with severe liver conditions hope to receive a liver transplant. However, brain-dead liver donors are scarce, and the majority of patients are not able to receive a transplant [8]. Recent statistics show that among 1,200 1,500 liver transplants in Korea in a year, approximately $60 \%$ were from living donors, while 17 28\% were from brain-dead donors [8]. Patients register on the waiting list of the Korean Organ Network for Organ Sharing and wait for an appropriate brain-dead donor [6]. While the decision to transition to life-sustaining care does not mean forfeiting one's position in the waiting list for a liver transplant, patients and their caregivers may misconstrue the decision as meaning that they are giving up on the possibility for a transplant [6]. Thus, end-stage liver disease patients need to have enough time to discuss these issues with their caregiver and to contemplate life-sustaining and palliative care, as well as possibly to receive a liver transplant [4].

It has been reported that between $7.1 \%$ and $11.0 \%$ of endstage liver disease patients request palliative care $[4,9]$. Despite the clinical significance of end-stage liver disease patients' decisions on life sustaining care, little research has focused on these patients [9], and little research in Korea has investigated the decision-making practices related to the unique situation faced by end-stage liver disease patients.

Therefore, we aimed to study the decision-making practices of patients with end-stage liver disease regarding lifesustaining care in the frontline clinical field after the Act on Decisions on Life-Sustaining Treatment came into force. We expect that our results will be utilized as baseline information for establishing policies and systems related to decisions on life-sustaining treatment that reflect the specific characteristics of end-stage liver disease.

\section{METHODS}

\section{Design}

This retrospective, descriptive survey was conducted to analyze decision-making practices regarding the discontinuation of life-sustaining treatment and the results of life-sustaining treatment in end-stage liver disease patients who wrote physician orders for life-sustaining treatment (POLST).

\section{Subjects}

The subjects of this study were patients who wrote POLSTs at general tertiary hospitals in Seoul from February 4, 2018, to August 31, 2018. The liver diseases of the patients analyzed in this study were hepatocellular carcinoma, liver cirrhosis, and hepatocellular carcinoma with liver cirrhosis.

\section{Tools}

The life-sustaining treatment research team, which included the authors of this article, selected items for the report form with reference to the literature related to life-sustaining care [2,9]. We then designed a case report form based on the POLST and electronic medical records in the hospitals where the research was conducted. The following specific items were 
included in the case report form:

1) General characteristics: gender, age, educational background, marital status, diagnosis, and other chronic comorbidities (e.g., diabetes, hepatitis, or renal disease).

2) Characteristics regarding POLST submission: the name of the patient or family member who completed the POLST; the reason why a family member prepared the paperwork; the patient's status when the POLST was written (terminal patient or patient in hospice care); consciousness of the patient; ability to perform daily routines (Eastern Cooperative Oncology Group [ECOG] performance status); ambulation status; instructions to discontinue life-sustaining treatment including cardiopulmonary resuscitation [CPR], artificial respiration, dialysis, or chemotherapy; the location where the POLST was prepared (outpatient care, inpatient care, intensive care unit, or emergency room); and willingness to enter hospice care.

3) The patient's life-sustaining treatment regimen: life-sustaining treatment practices (CPR, chemotherapy, radiotherapy, dialysis, use of a respirator, liver transplant, or admission to intensive care unit) before and after writing the POLST.

4) The results of life-sustaining treatment: patient's survival, additional appointments made by the patient and the circumstances of subsequent visits, location of death, and the number of days until discharge or death after the paperwork was completed.

5) For subjects who withdrew their POLST, the following factors were specifically analyzed: gender, age, the person who prepared the paperwork, the consciousness of the patient, the ability to perform daily routines, discontinued life-sustaining treatments (CPR, artificial respiration, dialysis, or chemotherapy), the reason to withdraw POLST, and whether the patient died.

\section{Data collection}

This research was approved by the Institutional Review Board (2018-1533). We collected the data through electronic medical records and POLST after the request to review patients' electronic medical records was approved. The period of data collection was from February 1, 2019 to April 30, 2019.

\section{Data analysis}

We analyzed the collected data using SPSS version 24 (IBM
Corp., Armonk, NY, USA). For the general characteristics and characteristics regarding writing the POLST, we calculated the mean and standard deviation of each item in absolute terms and as percentages. Each item related to life-sustaining practices before and after POLST submission is similarly presented as an absolute number and percentage. For the number of days until writing the POLST after admission and until discharge after writing the POLST, the range and median are also presented.

\section{RESULTS}

\section{General characteristics of subjects}

The minority $(18.8 \%)$ of the subjects were female, whereas Table 1. Characteristics of Subjects ( $N=101)$.

\begin{tabular}{|c|c|c|c|}
\hline Characteristics & Categories & $\mathrm{n}(\%)$ & Mean \pm SD \\
\hline \multirow[t]{2}{*}{ Gender } & Female & $19(18.8)$ & \\
\hline & Male & $82(81.2)$ & \\
\hline \multirow[t]{4}{*}{ Age (yr) } & $<50$ & $10(9.9)$ & \\
\hline & $50 \sim 59$ & $34(33.7)$ & \\
\hline & $60 \sim 69$ & $36(35.6)$ & \\
\hline & $\geq 70$ & $21(20.8)$ & $61.8 \pm 10.6$ \\
\hline \multirow[t]{4}{*}{ Education } & sElementary school & 19 (18.8) & \\
\hline & Middle school & $11(10.9)$ & \\
\hline & High school & $47(46.5)$ & \\
\hline & $\geq$ College & $24(23.8)$ & \\
\hline \multirow[t]{2}{*}{ Marital state } & Married & $91(90.1)$ & \\
\hline & Unmarried & $10(9.9)$ & \\
\hline \multirow[t]{2}{*}{ Residential district } & Metropolitan area & $65(64.4)$ & \\
\hline & Non-metropolitan area & $36(35.6)$ & \\
\hline \multirow[t]{3}{*}{ Diagnosis } & LConly & $16(15.8)$ & \\
\hline & HCC only & $9(8.9)$ & \\
\hline & HCC with LC & $76(75.3)$ & \\
\hline \multirow[t]{4}{*}{ Comorbidities* } & Hypertension & $31(30.7)$ & \\
\hline & Diabetes mellitus & $32(31.7)$ & \\
\hline & Hepatitis & $70(69.3)$ & \\
\hline & $\begin{array}{l}\text { Renal dysfunction } \\
(G F R<60)\end{array}$ & $42(41.6)$ & \\
\hline \multirow{5}{*}{$\begin{array}{l}\text { The number of } \\
\text { comorbidities }\end{array}$} & 0 & $6(5.9)$ & \\
\hline & 1 & $37(36.6)$ & \\
\hline & 2 & 39 (38.6) & \\
\hline & 3 & $16(15.8)$ & \\
\hline & 4 & $3(3.0)$ & $1.7 \pm 0.9$ \\
\hline
\end{tabular}

*Multiple response.

GFR: glomerular filtration rate, HCC: hepatocellular carcinoma, LC: liver cirrhosis. 
$81.2 \%$ were male, with an average age of $61.8( \pm 10.61)$ years. Furthermore, $15.8 \%$ of the subjects were diagnosed with liver cirrhosis, $8.9 \%$ were diagnosed with hepatocellular carcinoma, and $75.3 \%$ were diagnosed with hepatocellular carcinoma with liver cirrhosis (Table 1).

\section{Characteristics regarding POLST}

Sixty-three of the subjects (62.4\%) prepared their POLST by themselves, while the POLST was prepared by patients' fam-

Table 2. Characteristics of Physician Orders for Life-Sustaining Treatment $(\mathrm{N}=101)$.

\begin{tabular}{|c|c|c|}
\hline Characteristics & Categories & $\mathrm{n}(\%)$ \\
\hline \multirow[t]{2}{*}{ Decision maker } & Patient & $63(62.4)$ \\
\hline & Family & $38(37.6)$ \\
\hline \multirow[t]{3}{*}{$\begin{array}{l}\text { Reasons for family writing } \\
\text { the POLST }(n=38)\end{array}$} & $\begin{array}{l}\text { Consciousness change of } \\
\text { patient }\end{array}$ & $24(63.2)$ \\
\hline & Change of patient's condition & $7(18.4)$ \\
\hline & Unknown & $7(18.4)$ \\
\hline \multirow[t]{2}{*}{ Patient's state } & End-stage & $31(30.7)$ \\
\hline & In dying process & $70(69.3)$ \\
\hline \multirow[t]{5}{*}{ Level of Consciousness } & Alert & $49(48.5)$ \\
\hline & Confused & $31(30.7)$ \\
\hline & Drowsy & $12(11.9)$ \\
\hline & Stupor & $1(1.0)$ \\
\hline & Coma or sedated & $8(7.9)$ \\
\hline \multirow[t]{5}{*}{ ECOG performance status } & 0 & $1(1.0)$ \\
\hline & 1 & $5(4.9)$ \\
\hline & 2 & $25(24.8)$ \\
\hline & 3 & $21(20.8)$ \\
\hline & 4 & $49(48.5)$ \\
\hline \multirow[t]{4}{*}{ Ambulation } & Walking without assistance & $4(4.0)$ \\
\hline & Walking with assistance & $12(11.9)$ \\
\hline & Wheelchair & $34(33.6)$ \\
\hline & Stretcher & $51(50.5)$ \\
\hline \multirow[t]{4}{*}{ Refused treatment on POLST } & CPCR & $101(100.0)$ \\
\hline & Ventilator & $97(95.5)$ \\
\hline & Hemodialysis & $86(85.1)$ \\
\hline & Chemotherapy & $67(66.3)$ \\
\hline \multirow{4}{*}{$\begin{array}{l}\text { Place where POLST was } \\
\text { written }\end{array}$} & Ward & $91(90.1)$ \\
\hline & Intensive care unit & $7(6.9)$ \\
\hline & Outpatient department & $1(1.0)$ \\
\hline & Emergency room & $2(2.0)$ \\
\hline \multirow[t]{2}{*}{ Intent to use hospice care } & Yes & $42(41.6)$ \\
\hline & No & $59(58.4)$ \\
\hline \multirow{2}{*}{$\begin{array}{l}\text { Days from hospitalization to } \\
\text { POLST }\end{array}$} & Median (range) & 5 (0 134) \\
\hline & $M \pm S D$ & $13.4 \pm 22.3$ \\
\hline
\end{tabular}

CPCR: cardiopulmonary cerebral resuscitation, ECOG: eastern cooperative oncology group, POLST: physician orders for life-sustaining treatment. ily members in 38 cases (37.6\%). Family members prepared the POLST for reasons including the patient's diminished consciousness (24 cases, $63.2 \%$ ) or drastic deterioration of the patient's condition (7 cases, 18.4\%). According to physicians' determination of subjects' condition, 31 were terminal patients (31.8\%) and 70 were in hospice care programs (68.2\%). All 101 subjects (100\%) refused cardiopulmonary resuscitation. Other life-sustaining treatment practices refused by patients included the use of respirators (97 cases, 95.5\%), dialysis (86 cases, $85.1 \%$ ), and/or chemotherapy (67 cases, $66.3 \%$ ). The average number of days elapsed from admission until the POLST was prepared was $13.4( \pm 22.3)$ days, with a range of 0-134 days (Table 2).

\section{Comparison of treatment before and after subjects' decisions on life-sustaining care}

After POLST submission, two out of three patients who were receiving chemotherapy discontinued chemotherapy, while one patient started a new chemotherapy regimen. Two of the eight patients receiving hemodialysis discontinued treatment, while two other patients began receiving hemodialysis as part of their regimen. Seven patients were using a respirator when their POLST was written. Four patients were weaned from a respirator as their condition improved, while two others were required to be placed on respirators. One patient was receiving radiotherapy at the time of writing the POLST. That patient discontinued radiotherapy, while two other patients began radiotherapy. Prior to POLST submission, 10 patients were admitted to the intensive care unit (ICU), while only two patients were treated in the ICU after writing the POLST (Table 3).

Table 3. Changes of Life-Sustaining Treatment ( $N=101)$.

\begin{tabular}{lcccc}
\hline \multirow{2}{*}{ Treatment } & $\mathrm{n}(\%)$ & \multicolumn{3}{c}{ Changes of treatment after POLST } \\
\cline { 3 - 5 } & & $\begin{array}{c}\text { Continuation } \\
\mathrm{n}(\%)\end{array}$ & $\begin{array}{c}\text { Discontinuation } \\
\mathrm{n}(\%)\end{array}$ & $\begin{array}{c}\text { Addition } \\
\mathrm{n}(\%)\end{array}$ \\
\hline CPCR & $0(0.0)$ & $0(0.0)$ & $0(0.0)$ & $0(0.0)$ \\
Chemotherapy & $4(3.9)$ & $1(25.0)$ & $2(50.0)$ & $1(25.0)$ \\
Hemodialysis & $10(9.9)$ & $6(60.0)$ & $2(20.0)$ & $2(20.0)$ \\
Ventilator & $9(8.9)$ & $7(77.8)$ & $0(0.0)$ & $2(22.2)$ \\
Radiotherapy & $4(3.9)$ & $1(25.0)$ & $1(25.0)$ & $2(50.0)$ \\
Care in the ICU & $12(11.9)$ & $10(83.3)$ & $0(0.0)$ & $2(16.7)$ \\
\hline
\end{tabular}

CPCR: cardiopulmonary cerebral resuscitation, ICU: intensive care unit, POLST: physician orders for life-sustaining treatment. 


\section{Results of life-sustaining treatment}

Thirty-three patients (32.7\%) survived, while 68 patients (67.3\%) died. After discharge, 22 patients (21.8\%) became outpatients at the same institution, while 22 patients were transferred to other institutions. There were 14 (13.9\%) emergency room visits and 16 cases of readmission (15.8\%). The duration between writing the POLST until the date of discharge was $9.8( \pm 15.09)$ days on average, with a range from 0 to 100 days. Among the 68 deceased patients, 62 (61.4\%) died at the institution where they were originally treated, while six patients (5.9\%) died at other locations. The duration from writing the POLST until death ranged from 0 to 287 days, with an average of $24.9( \pm 51.5)$ days (Table 4$)$.

\section{Additional analysis for subjects who withdrew their POLST}

Three subjects withdrew their POLST. Two received liver transplants, while one went through chemotherapy (Table 5).

\section{DISCUSSION}

Through this research, we aimed to reach a better understanding of the current status of decisions on life-sustaining treatment made by end-stage liver disease patients in clinical practice, after the Life-Sustaining Care Decision Act came into force.

Table 4. Results of Life-Sustaining Treatment (N=101).

\begin{tabular}{llc}
\hline \multicolumn{1}{c}{ Characteristics } & \multicolumn{1}{c}{ Categories } & $\mathrm{n}(\%)$ \\
\hline Life or death status & Survival & $33(32.7)$ \\
& Death & $68(67.3)$ \\
Follow up* (excluding death) & Re-visit (yes) & $22(21.8)$ \\
& ER (yes) & $14(13.9)$ \\
& Re-admission (yes) & $16(15.8)$ \\
& Transfer (yes) & $22(21.8)$ \\
The days from POLST to & Median (range) & $4(0 \sim 100)$ \\
discharge (including death) & M \pm SD & $9.8 \pm 15.1$ \\
Place of death ( $\mathrm{n}=68$ ) & Our hospital & $62(61.4)$ \\
& Others & $6(5.9)$ \\
The days from POLST to death & Median (range) & $6(0 \sim 287)$ \\
(n=68) & $M \pm S D$ & $24.9 \pm 51.5$ \\
\hline
\end{tabular}

*Multiple response.

POLST: physician orders for life-sustaining treatment.
We found that $62.4 \%$ of POLSTs were prepared by patients themselves, which is a higher proportion than has been reported in other studies. In an analysis of data retrieved for a 1-year period after the Act on Decisions on Life-Sustaining Treatment came into force, it was reported that the determinations were made by the family in $67.7 \%$ of cases, while $32.2 \%$ of cases involved self-determination [10]. Another study that investigated who decided upon do-not-resuscitate (DNR) instructions, the patients made the final determination for themselves in only $1 \%$ of cases, while $47.2 \%$ of the cases were determined by patients' spouses and patient's children made the decision in the other $47.2 \%$ of the cases [11]. In this study, the reasons why family members prepared POLSTs were changes in the patient's consciousness and drastic deterioration of the patient's condition. This result corroborates another finding that decision-making regarding DNR is related to irreversible deterioration of the patient's condition [12]. Along with carcinoma, the progression of end-stage liver disease can show multiple cycles of recovery and deterioration [4]. Moreover, end-stage liver disease with hepatic encephalopathy can cause reversible changes in cognitive capacity.

The finding that in $48.5 \%$ of cases, the patient was alert when the POLST was written implies that the acute deterioration phase had passed at the time of POLST preparation. The experience of patients with hepatic encephalopathy needs to be

Table 5. Characteristics of Subjects Who Withdrew Physician Orders for LifeSustaining Treatment ( $N=3$ ).

\begin{tabular}{|c|c|c|c|}
\hline Characteristics & Case 1 & Case 2 & Case 3 \\
\hline Gender & Male & Female & Male \\
\hline Age (yrs) & 51 & 60 & 55 \\
\hline Decision maker & Patient & Family & Patient \\
\hline Level of consciousness & Alert & Confused & Alert \\
\hline ECOG performance status & 1 & 3 & 2 \\
\hline \multicolumn{4}{|l|}{ Refused treatment on POLST } \\
\hline CPCR & Yes & Yes & Yes \\
\hline Ventilator & Yes & Yes & Yes \\
\hline Chemotherapy & NO & Yes & Yes \\
\hline Hemodialysis & Yes & Yes & Yes \\
\hline $\begin{array}{l}\text { Reason for withdrawal } \\
\text { of POLST }\end{array}$ & $\mathrm{LT}$ & $\mathrm{LT}$ & Chemotherapy \\
\hline Survival status & Survival & Survival & Death \\
\hline
\end{tabular}


considered in light of the specific characteristics of liver disease patients for each end-stage liver disease patient to be able to exercise their right to self-determination.

In this study, we found that it took 13.4 days on average for a POLST to be written after admission to the institution. Since the subjects stayed at the institution for 23.2 days on average, it can be deduced that about 10 days of life-sustaining treatment had been provided in accordance with the POLST. This timing is late compared to a study reporting that decisions on DNR instructions for emergency room patients were made after 10 hours on average [13]. Since making earlier decisions regarding life-sustaining treatment can extend the time that the patient is unburdened by meaningless treatment and prepare the patient for death with dignity, we believe that it is necessary to provide ample information on the Act on Decisions on Life-Sustaining Treatment and to conduct a nationwide awareness-raising campaign.

However, for end-stage liver disease patients, who tend to experience repeated cycles of deterioration and recovery of their symptoms, more time is needed to decide on lifesustaining care than is the case for patients with other lifethreatening illnesses, because they may expect the possibility of a curative liver transplant. Therefore, it is important to determine the transition points between current treatment, liver transplantation, and life-sustaining treatment. Such decisions can be difficult, and the conceptions on the scope of lifesustaining treatment may differ between the medical team and the patient's family members [14]. Above all else, a patient's will at the stage of hospice care must be respected. The intention of the Act on Decisions on Life-Sustaining Treatment was to protect patients' autonomy, and doing so requires an open discussion with patients and their caregivers after providing them with realistic alternatives.

In this study, $41.6 \%$ of subjects who wrote POLSTs provided positive responses regarding their willingness to utilize hospice care. In contrast to a previous study reporting that only $13.8 \%$ of terminal cancer patients opted in for the use of hospice care [10], our findings reflect changes in recognition of the possibility of using the hospice care system. Appropriate and earlier implementation of palliative care in a hospice setting may reduce the frequency of admissions and visits to emergency rooms among patients suffering from chronic illness, which could reduce medical expenditures [14]. Medical teams must engage in appropriate communication so that the decisionmaking process reflects the opinions, values, and preferences of end-stage liver disease patients awaiting liver transplants and their families without prejudice. Furthermore, the medical team should be able to guide such patients and their caregivers through the process properly. Moreover, medical institutions should actively promote and support the submission of advanced treatment directives and the use of hospice care.

We also found that most life-sustaining treatment continued even after the POLST was written. The two subjects who sought additional life-sustaining treatment after written their POLSTs (respirator use, dialysis, and ICU care) were patients who received a liver transplant from brain-dead donors. It is a meaningful result that life-sustaining treatments that were deemed unnecessary or refused as part of the POLST became essential treatment again upon transplantation. Based on these findings, medical teams need to guide patients who require liver transplantation and their family members to discuss and make the decision, based on the progression and prognosis of the disease and the potential liver transplant.

Thirty-three (32.7\%) of the patients in this study survived, while more than twice as many $(68 ; 67.3 \%)$ died. The observation that $62(61.4 \%)$ of the 68 deaths occurred at the institution where the patient originally sought treatment underscores the need for medical institutions to prepare and plan life-sustaining treatments for end-stage liver disease patients. Each patient requires care for his or her distinct physical symptoms, such as pain, dyspnea, ascites, hemorrhage, and edema, as well as for emotional issues such as anxiety, depression, and a sense of regret, in addition to various complications that come with the disease. Therefore, approaches to palliative care through the hospice system, as well as various life-sustaining treatment regimens, should be given sufficient consideration. Moreover, medical institutions should make extensive efforts to offer a variety of care options actively.

The probability of regretting or withdrawing decisions on life-sustaining care increases when a patent has insufficient information on life-sustaining treatment or confusion in terms of their values [15], as well as when conflict exists between family members in the decision-making process on lifesustaining treatment or family members have significant dif- 
ferences of opinion on the direction of hospice care $[16,17]$. In contrast, the probability of revocation was found to be low when the patient made his or her own decision [16]. In many instances, patents reversed their decisions on life-sustaining treatment after they rendered their decisions, creating disparities between the treatments that patients officially authorized and the treatments that they actually received [18-20].

Among the three subjects who withdrew their POLST, two survived after receiving a liver transplant from a brain-dead donor, and the remaining one died after undergoing chemotherapy. The characteristics of each patient before revocation (e.g., consciousness and ECOG performance status) were similar. When a patient writes a POLST, he or she makes the decision to stop or suspend life-sustaining treatments, a category that does not include liver transplantation. Most endstage liver disease patients are on the waiting list for a full liver transplant from a brain-dead donor. Should a donor surface to provide the patient with a suitable liver, the patient withdraws his or her POLST, and then begins the procedure for a liver transplant. When the POLST is withdrawn, all the lifesustaining treatments for which discontinuation was requested become essential treatment for the patient.

Therefore, medical teams should provide sufficient explana- tion on the benefits, risks, value, and the likelihood of a liver transplant. After doing so, they need to support the choices made by the end-stage liver disease patient and establish systematic measures to ensure understanding between patients, caregivers, and medical professionals in terms of treatment goals. Intensive efforts such as organizing interdisciplinary teams composed of a wide range of professionals with ample knowledge and clinical experience in treating end-stage liver disease patients, discussing surgical methods with experts in liver transplant procedures and palliative care, and creating smooth channels of communication within the team and preparing effective guidelines.

\section{CONFLICT OF INTEREST}

No potential conflict of interest relevant to this article was reported.

\section{SUPPLEMENTARY MATERIALS}

Supplementary materials can be found via https://doi. $\operatorname{org} / 10.14475 / \mathrm{kjhpc} .2020 .23 .2 .85$.

\section{REFERENCES}

1. Ostgathe C, Alt-Epping B, Golla H, Gaertner J, Lindena G, Radbruch L, et al. Non-cancer patients in specialized palliative care in Germany: what are the problems? Palliat Med 2011;25:148-52.

2. Nam EJ, Lee SN, Lee R. Comparison of life-sustaining treatment in terminal cancer patients between a cancer and hospice unit after do-notresuscitate orders. Asian Oncol Nurs 2018;18:198-205.

3. Ryu GH. Consideration on the Life-Sustaining Treatment Decision System. Legal Theory Prac Rev 2019;7:191-211.

4. Kim MY. Hospice and palliative care in end stage liver disease. Korean J Hosp Palliat Care 2017;20:167-72.

5. Lim JW, Kim SY, Ke SS, Cho BL. The association chronic liver diseases with health related behaviors in South Korea. Korean J Fam Med 2010;31:302-07.

6. Shin JY, Yoon SJ, Kim SH, Lee ES, Koh SJ, Park JO. A qualitative study of physicians' perspectives on non-cancer hospice-palliative care in Korea: Focus on AIDS, COPD and Liver Cirrhosis. Korean J Hosp Palliat Care 2017;20:177-87.

7. Yun SY, Kang JY. Preferences for care near the end of life according to chronic patients' characteristics. J Korean Acad Adult Nurs 2013:25:207-18.

8. Yoo SY. Liver transplantation in the last 7 years: National Health Insurance Database Study. Sci Rep 2015;9:78-86.

9. Lee MA. Withdrawal of life-prolonging medical care and hospice-palliative care. J Korean Med Assoc 2019;62:369-75.

10. MOHW: Announcement [Internet]. Sejong: Ministry of Health and Welfare; 2019 [cited 2019 Feb 14]. Available from: https://www.mohw. go.kr.

11. Kang NY, Park JY. Clinical characteristics of oncologic patients with DNR decision at a tertiary hospital. Korean J Hosp Palliat Care 2016;19:26-33.

12. Kim HA. Changes in life sustaining treatment of terminally III cancer patient after do-not-resuscitate decision [master's thesis]. Ulsan: Ulsan Univ.; 2014. Korean. 
13. Kang SY. Characteristics and nursing activities of DNR patients in emergency room of a tertiary care hospital [master's thesis]. Busan: Pusan Univ.; 2016. Korean.

14. Kim DJ, Choi MS. Life-sustaining treatment and palliative care in patients with liver cirrhosis-legal, ethical, and practical issues. Clin Mol Hepatol 2017:23:115-22.

15. Choi JJ, Kim SH, Kim SW. Reversals in decisions about life-sustaining treatment and associated factors among older patients with terminal stage of cardiopulmonary disease. J Korean Acad Adult Nurs 2019;49:329-39.

16. Kim SH. Family surrogates' decision regret and psychological stress about end-of-life cancer treatments: Path analysis. J Korean Acad Adult Nurs 2018;48:578-87.

17. Han SY. A case study on Hospice Team's experience of the decision of patients' hospice and life sustaining treatments. Health Soc Welf Rev 2019;39:453-84.

18. Auriemma CL, Nguyen CA, Bronheim R, Kent S, Nadiger S, Pardo D, et al. Stability of end-of-life preferences: A systematic review of the evidence. JAMA Int Med 2014;174:1085-92.

19. Chavez G, Richman IB, Kaimal R, Bentley J, Yasukawa LA, Altman RB, et al. Reversals and limitations on high-intensity, life-sustaining treatments. PLoS One. 2018;13:e0190569.

20. Song MK, Ward SE, Hanson LC, Metzger M, Kim S. Determining consistency of surrogate decisions and end-of-life care received with patient goals-of-care preferences. J Palliat Med 2016;19:610-6. 